\title{
COMPLEMENTARY FEEDING PRACTICES: A PHENOMENOLOGICAL STUDY ON THE PERSPECTIVES OF FIRST-TIME MOTHERS IN THE EFFUTU MUNICIPALITY OF GHANA
}

\author{
Janet Agyarkwaa Oti ${ }^{11}$, \\ Theresa Alexandra $\mathbf{A m u}^{2}$ \\ ${ }^{1}$ Department of Food and Nutrition Education, \\ University of Education, \\ Winneba, Ghana \\ ${ }^{2} \mathrm{PhD}$, Department of Family Life Education, \\ University of Education, \\ Winneba, Ghana
}

\begin{abstract}
:
An important step in reducing infants' risk of being malnourished, contracting infectious diseases and their accompanying mortalities is to gain an understanding of the experiences of mothers' complementary feeding practices. While research exists on complementary feeding practices, limited research is documented on complementary feeding experiences of first-time mothers in Ghana with no evidence from the Effutu Municipality. In view of this lacuna in literature, this study investigated the lived experiences of first-time mothers on the initiation of complementary feeding in the Effutu Municipality using Social Constructivism as a theoretical foundation. The phenomenological research design within the interpretivism paradigm was followed in the conduct of the study where 12 first-time mothers were sampled through purposive and convenience sampling techniques with the main instrument being a semi-structured interview guide. After meeting the trustworthiness criteria, thematic analysis was used to analyze the data. The findings of the study revealed that first-time mothers initiated complementary feeding before the recommended period of six months. Besides, foods used in initiating complementary feeding were mostly cereal-based which is known to be deficient in other vital nutrients such as iron, zinc, phosphorus, magnesium, calcium, and vitamin B6 required and recommended for the healthy development of the child. The findings on experiences of first-time mothers towards complementary feeding indicated that they were inadequately prepared to initiate complementary feeding. Based on these results, it was recommended that the municipal health directorate should organize health promotion programmes to assist first-time mothers to better understand complementary
\end{abstract}

'Correspondence: email jannittaa@yahoo.com 
feeding with its accompanying positive consequences of improving child growth and development.

Keywords: complementary feeding, first-time mothers, infants

\section{Introduction}

Malnutrition, mortality, and morbidity among infants are regarded as a global public health concern in these modern times, with empirical data pointing to incorrect feeding practices as a key contributor. Consistent with this claim, it has been reported that globally, 5.3 million children under 5 years died in 2018 (World Health Organization, 2018). In 2020, the World Health Organization reported that 149 million children less than 5 years were estimated to be stunted (too short for their age) 45 million were estimated to be wasted (too thin for height) while around $45 \%$ of infants' morbidity are linked to undernutrition which mostly occurs in low to middle-income countries. Available evidence suggests that South Asian countries like Pakistan are noted to have the highest prevalence of undernutrition with stunting accounting for $40.2 \%$, wasting $17.7 \%$, and underweight $28.9 \%$ (United Nations Children Fund, UNICEF, 2020). It is believed that some of these situations could be traced to the initiation of complementary feeding; especially when it was started, how it was done, the kinds of food that were introduced, and the reactions of both mother and child. Therefore, there is the need for more research to generate very definitive and compelling evidence such as the lived experiences of firsttime mothers on their practice of complementary feeding.

Consistent with these findings, African countries such as Ethiopia and Ghana continue to show limited progress towards the attainment of Target 3.2 of goal 3 of the Sustainable Development Goals which among other things aim to avoid and end preventable death of infants before attaining age 5. For instance, in Ethiopia, the rate of stunting, underweight, and wasting among infants under 5 years was 37\%, 21\%, and 7\% respectively (Ethiopia Mini-Demographic and Health Survey, 2019). In Ghana, available statistics have revealed that $28 \%$ of all infants under 5 years are stunted with about half of these children being between 6-23months after birth and that 1 out of every 24 Ghanaian children dies before age 1, and 1 in every 17 dies before age 5 with maternal mortality being 319 per 100,000 live births (Schmidt-Traub, Kroll, Durand-Delacre, Teksoz \& Sachs, 2017; Ghana Statistical Service, 2015; Ghana Health Service, 2015). This available evidence suggests that malnutrition is a major cause of infant mortality and morbidity, and therefore, an affront to infant wellbeing. Accordingly, there is the need for a sustained effort not only in halting the phenomenon but to as well reverse the situation by exploring strategies in specific settings that would lead to recommendations on the best strategies for ensuring child survival and their long time well-being.

In arguing for the essence of the introduction of complementary feeding for an infant after 6 months, the World Health Organization (2017) maintained that after 6 months, exclusive breastfeeding is not adequate to meet the growing nutritional 
demands of infants and therefore, calls for the introduction of complementary feeding to augment breast milk. However, this transition process if not well implemented, could be injurious to the child. Consequently, food and nutrition experts and public health practitioners have underscored the prominence of complementary feeding as one of the fundamental core mechanisms and a key prerequisite in ensuring optimal growth and development among children. Explained as the gradual process of introducing any solid, semi-solid or soft food, that is either manufactured or locally prepared, and is suitable as a complement to breast milk when breast milk becomes insufficient to satisfy the nutritional requirements of the infant (Haruna, 2018). This period apart from being a window for tremendous growth and development is also an epoch where infants become susceptible to nutrient deficiencies and excesses and marked dietary changes as children are exposed to new foods, tastes, and feeding experiences (Kostecka, Jackowska \& Kostecka, 2020). In essence, complementary feeding though beneficial could become a dangerous means of making infants susceptible to infectious diseases if not properly executed. It is assumed that first-time mothers are susceptible to engaging in excesses that are likely to have varied outcomes for their children because of a lack of knowledge, skills, and will to prudently introduce complementary feeding. Hence, understanding the experiences especially from first-time mothers is a step towards realizing desired complementary feeding.

To curb the dangers associated with the introduction of complementary feeding, World Health Organization (2010) has advanced eight-core indicators guiding appropriate complementary feeding practices. These include: 1) early start of breastfeeding; (2) exclusive breastfeeding under 6 months; (3) sustained breastfeeding for 1 year; (4) the introduction of solid, semi-solid or soft foods; (5) minimum dietary diversity; (6) minimum meal frequency; (7) minimum acceptable diet; and (8) consumption of iron-rich or iron-fortified foods. Besides, WHO's recommendations, countries have evolved nationwide indicators as a guide to the effective practice of complementary feeding, for instance, the Ghana Health Service's (2015) Child Welfare Clinic (CWC) and Ghana Promotion of Complementary Feeding Practices Project, 2011. These interventions over the years had focused on empowering mothers to become competent to practice appropriate childcare, feeding especially during the first 1000 days of the infants and the general wellbeing of their children (Bentil, Steiner-Aseidu \& Lartey, 2016; Gyampoh, Otoo \& Aryeetey, 2014). In line with these, it is concluded that at global and national levels there have been interventions aimed at accelerating momentum to improve appropriate complementary feeding practices.

In spite of these interventions, optimal complementary feeding practices remain a challenge around the world. In developing countries, it has been discovered that one out of every six children is being fed a diet that meets the least possible requirements for healthy growth and development. (Begin \& Aguayo, 2017). In Africa, evidence from Cross River State in Nigeria by Udoh and Amodu (2016) revealed that $31.5 \%$ of children aged 6-23 months meet the minimum diet diversity with $36.5 \%$ meeting minimum meal frequency and $7.3 \%$ receiving acceptable diet. Similarly, evidence from a community 
based cross-sectional study on children aged 6-24 months in North West Ethiopia found $63 \%$ of the children received minimum meal frequency, $9.8 \%$ for minimum diet diversity, and only $8.6 \%$ received the minimum acceptable diet (Mulat, Alem, Woyraw \& Temesgen, 2019).

In Ghana, Haruna's (2018) study on factors influencing optimal complementary feeding practices among mothers of children aged 6-23 months, discovered that only $67.1 \%$ of all children between the ages of 6-23 months were introduced solids at the recommended age of 6 months. For all children aged 6-23 months, 65\% achieved minimum meal frequency (MMF), 33\% achieved minimum dietary diversity (MDD) and $24.3 \%$ achieved minimum adequate diet (MAD). National estimates by the Ghana Statistical Service (2015) have unveiled that 52\% of infants in their first 6 months of life are exclusively breastfed whilst only 13\% of children within the ages of 6 months and 23 months of age receive optimal complementary feeding. With these revelations, there is proof that optimal complementary feeding practices are a challenge due to the noncompliance with WHO's guidelines on complementary feeding practices.

Meanwhile, extant research has indicated that adherence to the health guidelines on complementary feeding is influenced by a myriad of factors such as socio-economic, cultural, and personal related factors with much less awareness on how complementary feeding practices vary across diverse populations around the globe (Cook, Powell. Ali, Penn-Jones, Ocheng \& Randhawa, 2020). On the part of Njai and Dixey (2013), mothers' socioeconomic status, income level, cultural and traditional practices very well influence the early introduction of complementary foods and henceforth lead to changes in their infant feeding practices. In another study, Mokori, Schonfeldt, and Hendricks (2017) found out that immunization, deworming, and age of the child were associated with complementary feeding practices. Other researchers have identified mother's decisionmaking role, attendance of the postnatal clinic, and receiving advice on child feeding from family, friends and neighbours are closely associated with complementary feeding (Chapagain 2013; Molla, Esigu \& Nega, 2017).

However, maternal age, maternal knowledge, child illness, poverty, early and single motherhood, poor social and professional support, poor knowledge, myths and misconceptions, and unintended pregnancies are major bottlenecks affecting the practice of optimal complementary practices with complementary feeding as key determinants of complementary feeding practices (Korir, 2013; Kimani-Murage, Fotso, Egondi, Abuya, Elungata, Zirabli \& Madise, 2014). It could be said that these might not be the only main reasons for the challenges to optimal complementary feeding practices among mothers. Besides, cursory scrutiny from these studies reveals that these studies adopted quantitative methodologies in their inquiries in understanding the phenomenon and therefore gave little or no account on the lived experiences from the mothers who initiate complementary feeding. Hence, it is prudent that other studies adopt methodologies that acknowledge the complexity in human interactions and social behaviours, and views knowledge as not only created through interpretations that people give to social constructs but also being created through the interpretations that people give to social 
constructs (Saunders, Lewis \& Thornhill, 2016) as to give a true picture of the practice of complementary feeding. Therefore, while knowledge is growing regarding the challenges to appropriate complementary feeding practices from different cultural backgrounds, less is known about the lived experiences of first-time mothers in contextspecific settings in Ghana. This study explored the lived experiences of first-time mothers on complementary feeding practices.

Optimum nutrition has been identified as a fuel to life in all human stages, with much emphasis made on the period between 6-23 months of every infant's life, documented as the most critical window in promoting optimal child growth and development (Haruna, 2018). Consistent with this claim, the WHO (2010) has advocated for strict compliance of mothers in adhering to the guidelines on complementary feeding practices. This is based on evidence from previous study by Awobgenja and Ugwuona (2010), reporting the link between infants' poor nutritional status and mothers' knowledge in initiating complementary feeding.

Furthermore, studies by Saaka, Larbi, Mutaru, and Hoeschle-zeledon (2016) from 45 districts in the northern enclave of Ghana revealed appropriate complementary feeding practices of only $15.7 \%$ whereas studies from the Greater Accra Region recorded the prevalence of optimal complementary feeding practices to be $21 \%, 38 \%$ and $32 \%$ for Ga West, Tema, and Ashaiman Metropolitan area and Accra Metropolitan enclave respectively (Agbozo, Colecraft, \& Ellahi, 2015; Bentil et al., 2016 \& Gyampoh, et al., 2014). Even though the aforementioned evidence reveal that an attempt has been made in recent past to uncover the nature of complementary feeding in Ghana, it is also clear that studies on complementary feeding in the Effutu Municipality is rare.

Besides, a cursory observation from neighbourhoods and anecdotal evidence from the Municipality identified some toddlers with some unhealthy physiques such as protruding bellies, pale faces, bulging eyes, unhealthy hair growth, poor skin growth etc. Perhaps, these conditions seem not to be reported at the various health centres because mothers were noticed by public health personnel to be irregular for postnatal visits making it difficult in monitoring their baby's growth. Besides, the WHO (2015) have reported that just a few women avail themselves for postnatal visit within the early days of giving birth, and experts recommend that a woman should be evaluated by a health professional within 24 hours of giving birth, as well as discuss with the new mother the timing of additional postnatal appointments for the baby's immunization schedule.

Meanwhile, the World Health Organization (WHO) has recently updated the worldwide recommendations on postnatal care for women and babies through a technical consultation process. The updated guidelines address the timing and content of postpartum care for both mothers and babies.

In line with the fact that 6-23 months period of infants is the most critical window in promoting optimal child growth and development, there is a need to revisit research on first-time mothers' experiences on the initiation of complementary feeding so as to identify the challenges encountered when practicing complementary feeding at their inception and effectively manage them. Without this knowledge, the fight to arrest the 
adverse and multi-dimensional health and developmental consequences associated with suboptimal complementary feeding would be a mirage. Besides, previous studies conducted in other parts of Ghana have failed to uncover the lived experiences of firsttime mothers and have predominantly adopted the positivist paradigm, utilizing quantitative approaches in investigating trends on complementary feeding. Drawing on Harrison, Brodribb, and Hepworth (2017) call for stakeholders to address the confusion mothers experience on complementary feeding guidelines, including knowing what to feed and how to engage in healthy infant feeding, this study becomes relevant. The following research questions guided the study:

1) At what age do first-time mothers initiate complementary feeding to their babies?

2) What foods do mothers introduce their babies to and how is it introduced?

3) How do first-time mothers experience the initiation of complementary feeding?

It is hoped that the findings of the study would be helpful in a number of ways. Firstly, the outcome of the study would expose health administrators, and food and nutrition practitioners to get a deeper understanding of the everyday experiences of firsttime mothers on complementary feeding practices which would enable them to implement strategies not to only assist first-time mothers but also nursing mothers, in general, to cope with the confusion and anxiety associated with the practice of complementary feeding. Secondly, the outcome of the study would bring to bear the foods nursing mothers usually use during complementary feeding so that the extent to which parents follow the recommended diets could be determined and for improved child health. Besides, the results of the study would expand the frontiers of knowledge in the field of complementary feeding practices, especially with first-time mothers. Finally, the findings of the study would guide the Winneba Municipal Health Directorate to design and implement workable programmes to raise awareness of the dangers associated with subnormal feeding practices among nursing mothers which would lead to enhanced child health in the Municipality and beyond.

\section{Theoretical Underpinning of the Study}

The theory of social constructivism constituted the theoretical framework of the study. Constructivist research, according to Creswell and Poth (2018), does not begin with a hypothesis about the topic of interest; rather, it creates a theory or pattern of meaning by interpreting what is learned throughout the investigation. Besides, multiple realities exist and are contingent on the individual, according to social constructivism (Denzin \& Lincoln, 2011). Social constructivism suggests that individuals attempt to comprehend the environment in which they live and work (Creswell \& Poth, 2018). As such individuals generate subjective meanings of their experiences, according to Denzin and Lincoln (2011), because knowledge is socially constructed. In linking this theory to the study, it could be said that first-time mothers construct a reality to complementary feeding that is uniquely theirs. Often times these meanings are formed through interactions with others, historical norms, and cultural norms (Creswell \& Poth, 2018). 
This study, therefore, adopted social constructivism as the theoretical lens so as to comprehend the experiences of first-time mothers on complementary feeding, because of the way first-time mothers construct reality with complementary feeding through unique life experiences.

\section{Methodology}

This study employed the interpretivist paradigm in line with the qualitative approach. The interpretivist stance is consistent with the argument that it acknowledges the complexity in human interactions and social behaviours and views knowledge as being created through interpretations that people give to social constructs (Saunders, Lewis \& Thornhill, 2016). Therefore, the interpretivists conceptualize knowledge as the subjective view of the social actors. Besides, Creswell and Poth (2018) maintained that qualitative research is directed to issues that need to be explored by identifying variables that cannot easily be measured or to better hear silenced voices. As a result, an in-depth study of the lived experiences of first-time mothers on complementary feeding practices is needed to understand the unknown sides of complementary feeding practices of first-time mothers. This approach was deemed fit for the study because the researchers were interested in capturing a deeper understanding of the time first-time mothers initiate complementary feeding, the foods used to initiate complementary feeding as well as the lived experiences on complementary feeding practices.

This study adopted the phenomenology research design. Phenomenological methodology aims to explore and describe a common phenomenon or reality experienced by many individuals. Accordingly, the phenomenology research design is well suited to the purpose of this study which sought to explore the common realism of individuals who have experienced a shared phenomenon, such as first-time mothers who have experienced the transition from milk feeding to complementary feeding. Additionally, the qualitative approach offers this study the impetus of creating themes to answer research questions as well as to create textural and structural descriptions to understand the participants' experience with complementary feeding.

Qualitative researchers advocate for a small sample size due to the rich and volume of data collected (Burns \& Grove, 2011). Researchers support small sample sizes in qualitative studies because it reduces time constraints of the interviewing process, and the transcription of the interview data (Parahoo, 2006). Whereas Creswell (2002) recommends 3-5 participants, Whitehead and Annells (2007) recommend 8-15 participants in qualitative studies. Therefore, 12 first-time mothers with children aged between 6-24 months who visited the Trauma Specialist Hospital, the Municipal Hospital, and the Municipal Health Centre for post-natal services were selected for the study through purposive and convenience sampling techniques. The data collection spanned a period of one week. The researchers discussed with the first-time mothers and agreed on the time and venue for the interviews. This was in line with Burns and Grove's (2011) suggestion that effective interviews require a venue and time that would make 
participants comfortable, and devoid of disruptions. With the consent of the interviewees, the interviews were carried out at their location of choice. The researchers sought permission from the participants and recorded the interviews to ensure completeness in data capture.

The main instrument for the study was a semi-structured interview guide which was self-constructed along with the research questions. All the questions were openended consisting of a set of questions carefully worded and arranged with the intention of taking each respondent through the same sequence of issues by asking them the same questions using essentially the same words to minimize variation in the questions being posed. This interview protocol reduces the interviewer effect and facilitates data analysis (Patton, 2015). The researchers chose the face-to-face interviews because it helps to establish rapport with the participants, motivate them, and any discomfort, stress, or problem that the participant's experience can be detected through frowns, and other body languages that are unconsciously exhibited which would be difficult to detect in a telephone interview (Sekaran \& Bougie, 2016). Therefore, the interviews made the data collection process more natural and conversational, hence making the participants relaxed in the process. The interview recordings were played and transcribed. Data transcription involves listening to each of the interviews and writing the information verbatim into text (Polit \& Beck, 2010). The hand-written text was then typed in a word document, saved on a laptop computer, and transcribed. The researchers then read through the text data and corrected all errors in terms of spelling errors, and missing words.

The thematic approach was followed to analyze the data. The thematic approach involves the use of themes and patterns developed from the data collected based on the research questions backing the study (Silverman, 2010). Thematic analysis allows the researcher to identify, analyze and report themes within the data collected (Braun \& Clarke, 2006). The data was then explored to help the researchers to familiarize with the data. The data exploration enabled the researchers to identify patterns of information that were vital to facilitate the coding process. The data were then coded. Boeije (2010) described data coding as the process of categorizing, assigning, or labelling segments of data with a word, a short phrase or a short name. This means that in the coding process, the researchers created categories in the research data and named them as codes.

The researchers used the theming data coding. This involves the use of phrases or sentences to describe an aspect of data (Saldana, 2013). Here, the researchers developed codes from the literature reviewed, read through the interview transcripts, identified relevant information in line with the themes, and copied and dropped them in the related codes. In the view of Myers (2009), the purpose of coding is to help researchers draw meaningful conclusions about the data, and assist the researcher in familiarizing with the data, recognizing the meaning of the data, and exploring the connection of the data. In addition, Corbin and Strauss (2008) emphasized that coding helps the researcher to extract and develop concepts from raw data in relation to their dimensions and 
characteristics. In the analysis, the researchers used statements made by the interviewees in relation to the themes.

Trustworthiness criteria in qualitative studies such as credibility, dependability, confirmability, and transferability were adhered to. Trochim (2006) argued that it is only the participants who are able to correctly judge the credibility of findings. Therefore, the researchers asked the interviewees to listen to the interview recordings, and they confirmed that the information was an accurate representation of their views. Dependability, which is similar to reliability in quantitative research, was ensured when the researchers gave a vivid description of the research process. For confirmability, the researchers developed the interview questions based on research questions that guided the study. For transferability, the researchers vividly described the context of the study so that anybody who wishes to generalize the findings to other contexts could identify the similarities in the settings and the possibility for such generalizations. Ethical issues such as access, confidentiality, anonymity, and informed consent were adhered to in the study.

\section{Analysis and Discussion of the Data from the Research Questions}

Research Question 1: At what age do first-time mothers initiate complementary feeding to their babies?

This research question explored the baby's age at which complementary feed was introduced. With this research question, the data gathered were categorized under themes such that theme 1 gives an account on initiation of complementary feeding by first-time mothers from birth to 4 months, theme 2 presents initiation of complementary feeding from 4-6 months of age, theme 3 detailed the account on complementary feeding from 6 months of age. First-time mothers elucidated their stance based on personal reasons which have been captured in the excerpts below:

Theme 1: Initiation from 0-4 months of age

This theme captures excerpts from first-time mothers who initiate complementary feeding from 0-4 months of age. Mother one expressed her sentiment:

"My story is very hard, hmmm for me I had an issue with breast milk production. My body system was unable to produce breast milk for my baby. Initially, after delivery, my midwife told me it was a bit normal in the cases of first-time mothers because the system is now adjusting itself which could take 2 to 3 days before it flows. After my consistent trial for my baby to suck, I still didn't get milk and of course, my baby must survive so I had to resort to the breast milk supplement, (SMA) I started with that for 3 months. I then introduced another pre-prepared baby food until she turned 6 months."

It could be deduced from the preceding excerpt that hormonal dysfunction can be a major push factor for the early introduction of complementary feeding. 
Another mother had this to say:

"I am a working mother whose work schedule demands that I get to work as early as possible. My work policy on motherhood includes the fact that when you deliver, you enjoy 3-months of maternity leave, so when I delivered, I enjoyed my maternity leave and had the opportunity to feed my baby constantly on the breast milk. But right after the resumption of duty; that is, when my son was 3 months old, I had to express the milk for him but he did not drink it. He always rejected the bottle with the expressed breast milk until I return home after work to feed him. My mum then suggested we try giving him real food to see if he will eat. Lo and behold we tried it and he ate so happily that it became a routine for him to eat complementary food whiles I was away and then feed him on the breast when I come back home. So indeed, my baby started feeding as early as 3 months 2 weeks."

It is implied from the excerpt above that the demand from a paid job was not delimited to just the individual but also her dependent, causing an early initiation of complementary feeding.

In the course of soliciting information from the fresh mothers, there was an emerging category with the age range of mothers. The following excerpts are from younger mothers in the category of 15-18years of age:

"Madam please I didn't produce breast milk after delivery, so after 2 days my baby was served with NAN 1 instant milk formula. After the introduction, I felt severely ill for 2 months and also constantly experienced pains in my breast. This hindered the flow of breast milk. My baby continued feeding on the instant formula until 3 months of age when I recovered from my ailment and started producing milk for my baby. Since he had not breastfed since birth there was a little challenge with him sucking. He poopo anytime I feed him with the breastmilk so I was advised to extract the initial milk from the breast since it was yellow. My grandma later gave him cerelac at 3months 3 weeks old and he ate very well and took the breast milk alongside."

It is clear from the excerpt above that the affordances of the initiation of complementary feeding varies and the unexpected such as illness is no exception as expressed by the young mother and this could have a stern effect on the infant.

Another young mother shared similar claims:

"My baby is 3 months 2 weeks, I gave him infant formula when he was 1 month old because the breast milk production was less but he rejected after one week so I stopped and just at 3 months I started complementary feeding, I fed him with cerelac. He had loose stool, so I became indecisive about whether to continue or to stop. I have decided to give him some time and continue later." 
It is inferred from the excerpt that breast milk production ability differs in every woman's case and can be a benchmark for the early initiation of complementary feed as expressed by a new mother.

Generally, it is deduced from the expressed sentiments of mothers that certain uncontrollable factors such as hormonal dysfunction, work demand, and illnesses are attributes to the early introduction of complementary feed.

Theme 2: Initiation from 4-6 months of age

This theme captures excerpts from first-time mothers who initiate complementary feeding from 4-6 months of age. A new mum expressed her claims:

"I started my baby's complementary feeding from the $4^{\text {th }}$ month though I knew it was very early. I did it out of frustration because my baby cried too much both day and night making me unable to rest adequately. I was advised by my grandmother that the breast milk might be insufficient for her and that she was not getting satisfied after a feed so I decided to feed her on semi-solid foods as advised. When I introduced the complementary food for the first time, she ate it very well and after that, she slept for so long a time that I was motivated to continue, that is how I started with the complementary feed."

It is can be deduced from this excerpt that the frustrations from a baby's cry can trigger the initiation of complementary feeding.

Sharing a similar viewpoint another first-time mother had this to say:

"My baby always cries and looks at my face any time I am eating so I once tried giving her a little of what I was eating and he ate it. based on this, I felt he did not like the taste of breast milk. His reaction to the introduction of solid food made me start complementary feeding when he was four months old."

The curiosity of babies in some cases influences their mothers to disregard the recommended age for complementary feeding and this is seen in the preceding excerpt.

Furthermore, it is iterated in the excerpt below that work-related stress has implications with respect to the initiation of complementary food within 4-6 months:

"The work I do does not permit me to breastfeed my baby as expected. Also, due to work stress, I am not able to produce more breast milk making her unable to gain much weight. Due to this, I had to start complementary feeding at 4 months."

It can be deduced from the above excerpt that the early introduction of complementary feed is as a result of work stress playing a key role in the breast milk production of the nursing mother in order to abide by the recommended 6 months of exclusive breastfeeding. 
Again, the excerpt below reveals the view of a young first-time mother in the category 15 to 18 years:

"Please my baby is 5 months 2 weeks old now but I have started feeding her already. I started when she was 5 months old. In fact, my baby can cry 'paa' so I felt she does not get satisfied after feeding on the breast so I decided to give her extra food that was how and why I started complementary feeding at that age."

It could be deduced from the shared experiences of new mothers that the quest for infants to gain weight, work stress, infant gestures showing readiness to eat, accounted for the early initiation of complementary feeding.

Theme 3: Initiation from 6 months of age

While some of the mothers fed their babies prior to 6 months due to personal experiences others were very skeptical and cautious with respect to initiating complementary feeding being new mothers. Below are excerpts validating this claim.

From a new mother's perspective:

"As for me, I was being very careful so I waited till my baby was 6 months before I started complementary feeding though at a point in time she cried too much and I felt she was not getting satisfied, yet I waited."

Another new mother shared a similar thought as expressed in the excerpt below:

"I was very ready to introduce complementary feeding before the statutory 6 months until a friend shared with me the experience she had. She said she rushed to feed her baby when he was not up to 6 months and she ended up with him at the hospital for a month because he caught a serious infection. This really made me cautious even though my mother kept telling me to give my baby food and nothing will happen to him but I did not listen to her and waited till my baby was six months before I started the complementary feeding."

Exclusive breastfeeding for 6 months was however practiced by a few new mothers for the fear of not knowing how the baby will react to the feed and perhaps catching an infection as emphasized in the preceding excerpts.

Data gathered on research question one revealed that most of the first-time mothers introduced complementary feeding to their babies earlier than the recommended 6 months of age as documented in literature.

Research Question 2: What foods do mothers introduce their babies to and how is it introduced? 
This research question sought to explore the foods the first-time mothers introduce their babies to and how it was introduced. Findings from the study revealed an array of views which are captured in the excerpts below:

"My introduction of complementary feed was by try and error mode. Hmm, I first started with cerelac, my baby rejected all the varieties of cerelac I introduced him to, then I tried maize porridge with a little sugar for taste which he enjoyed very well. I then decided to stick to that for one month before I change again to something else."

It is deduced from the foregoing excerpt that a home-prepared meal was a preferred choice in starting complementary feeding than pre-prepared meals which needs little preparation time.

Another new mother shared her view:

"I remember when my baby was aged 5 months and some weeks, I travelled and did not know I will spend that much time. He turned 6 months when we had not returned from our journey so I decided to introduce him to cerelac because of its short preparation time. He ate just a little on day one but accepted it fully after a week of introduction. He fed on it for a while because I kept changing the flavour. I then prepared weanimix for him when I returned home, and he ate that as well."

Again, in response to the exact food given to their babies a new mother had this to say:

"My girl started feeding on semi-solids at age 5 months 3 weeks with already prepared egg custard. Even though my parents advised that feeding her with egg can delay speech, I still continued to feed her with it. It is very creamy, tastes very sweet and is ready to eat, so she didn't reject it at all. I just decided to vary it by giving cream porridge and custard pudding which she enjoyed. In fact, I once gave her banku and soup but she rejected it. It made me think that she is not ready for home-made foods."

It is again inferred from the above excerpts that some mothers initiated complementary feeding with convenience foods because it tastes sweeter and has a short cooking time and stake to them because of their babies' positive reactions to them.

Other first-time mothers started feeding their babies with specific food commodities prepared at home.

"I started my boy with mashed kenkey with a little lactogen added. I made sure it was warm before giving it because I started his feed very early. Since he was new to it, I started bit by bit until he fully accepted it then I switched to weanimix."

Another new mother shared this: 
"My baby really gave me a tough time because he doesn't like food. I started his feed early with light maize porridge, he rejected it several times, I tried cerelac he again rejected it. I was then told to try millet porridge which I did and he accepted. I realized he enjoyed it so I didn't change it at all, I constantly gave him the millet porridge."

It was again expressed by a young new mother that:

"I started my baby with very light maize porridge. When given for the first time, she ate just a little, after 2 days she started eating an appreciable amount and that is how I started her feed. I later gave her tom brown made from rice and maize, she accepted this too and this motivated me to try other recipes."

These excerpts show that mothers tried different recipes but the most preferred by their babies is what is fed and in spite of the numerous trials, mothers resorted to giving home-prepared meals especially those mainly preferred by their babies and served at acceptable temperatures.

While some first mothers feed their babies with already prepared foods, others indicated they feed their babies with meals prepared for the whole family. Their views have been captured in the excerpts below:

"I started my baby with blended oats porridge, she took just a little. I prepared banku and okro soup for myself and my husband, while eating she constantly stared at me so I decided to give her some and to my surprise, she finished everything in the bowl with me. So. from there, I realized she loved it so I started feeding her with banku and okro soup which made her very fat."

Another mother shared a similar experience:

"I started complementary feeding at the exact recommended age and I was told that at that age they can eat anything we eat so I gave him soft rice ball with groundnut soup prepared for the family. I did not really prepare anything special for him but whatever we eat as a family I give him the same, just that if what we eat is not soft, I press at my fingertips to make it softer. He had an issue with pepper, so what I do is to reduce it in the meal for all. He ate everything given him and never showed signs of discomfort or health problem."

It is construed from the above excerpts that some babies loved to eat what their mothers eat making mothers resort to feeding them with the family's meal.

Data gathered on research question two disclosed that first-time mothers explored feeding their babies on foods ranging from convenience foods, home-prepared baby foods and prepared family meals. Besides, a cursory observation of home-prepared baby foods figured out that such foods were usually cereal-based and lack protein. 
Interestingly, the only mother who weaned her baby using food with some protein content was cautioned to stop by her parents with the myth that eggs had the potential of delaying speech in children.

Research Question 3: How do first-time mothers experience the initiation of complementary feeding?

Research question three sought to explore the experiences of first-time mothers with the initiation of complementary feeding. The experiences of these mothers have been captioned under the following themes as being a greenhorn at the start, a plethora of emotions and feelings, a moment of stress, an opportunity to know your baby and an avenue for fun and exposure.

Theme 1: "Being a Greenhorn at the start"

A common theme that emerged from the shared experiences of the first-time mothers was the challenges faced trying to initiate their infants to complementary feeding. The first-time mothers indicated that they started and experienced complementary feeding as being 'greenhorns' and seeing themselves as novices navigating through the motherhood cycle. Excerpts from the data confirmed this claim:

"In fact, weaning a baby is a big task, talk less of being a first-time mom. For me I had to call almost every mother I knew to help me out with the best food to start with because my baby did not like to eat anything aside from the breast milk so I kept trying and had to force him a little to eat."

Another mother shared a similar experience:

"It was a hustle starting my baby with complementary feeding, I had to browse all night to figure out which food was best to start with, what consistency to be served, and at what temperature. Even though I gathered information from the browsing that I did, getting my baby to eat was not easy, I had to experiment with different kinds of food before finally, he settled on roasted milled rice porridge."

It is clear from the preceding excerpts that complementary feeding for first-time mothers could be seen as a period of uncertainty. There is always the need for a push to move to what's next.

Some new mothers also described the introduction of complementary feeding as a 'try and win' and this is outlined in the assertion below:

"Hmm, when I began feeding my baby at 4 months old, I had a keen interest in what her 'poopo' will be like because I heard that immediately semi-solids are introduced, they have the possibility of constipating. I was really praying she does not experience that because if she does I cannot figure a way out." 
Another new mother shared a similar experience as captured in the excerpt below:

"I will term my experience as 'mixed understanding'. I consulted family and friends for their views on starting complementary feeding because I started my girl at a very tender age. In fact, each person's opinion was shared differently, some contradicted others and some had similar views, so as a novice, at a point in time, I was totally confused and had to practice any that I felt will suit me and thereafter I learnt from it."

To some mothers, introducing complementary feed was a time to figure out a problem with a solution as expressed in the foregoing excerpts.

Theme 2: "Plethora of emotions and feelings"

Another mutual theme among the respondents was the contradictory range of emotions and feelings shown in response to complementary feeding. According to the findings of this study, the switch to complementary feeding was accompanied by a range of emotions ranging from boredom to excitement. This is captured in the following excerpts:

"I will say that being a mother to your first child is joy, you are so focused on what your baby does, from sleeping, waking up to eating. Hmmm, beginning complementary feeding is one thing on its own. I certainly monitored what my baby does and was alert on what food he enjoyed and those he rejected because I varied the food, I introduce him with."

Another mother shared a similar opinion:

"This is my first child so I sometimes wished to pamper her and not to be too hard on her to eat, but hmmm when feeding gets frustrating I then get furious. But 'hey' I cannot beat my baby or force her to eat because if I do so she will cry to disturb me and no one else."

It is deduced from the excerpts above that introducing complementary feed by new mothers was a time they appreciated being mothers and of course, being a mother to their first child and therefore needed critical observation and monitoring to know what is preferred by their babies.

Some of the mothers again described the initiating period as "mix feelings", this is expressed in the statements below:

"I love that moment when I started to feed my baby. This is because I love kids' stuff like their spoons, feeding bottles and bowls, they look so tiny and nice. I enjoy using them to feed my baby and caring for them after use is fun to me."

Another mother shared a similar feeling: 
"Feeding a baby is interesting, I will say my baby feeds well. The moment I prepare her porridge in her bottle I see her giggling and immediately I fix it in her mouth she sucks without hesitation. I enjoy observing her feed. I sometimes intentionally remove the feeding bottle from her mouth when she is not done, she starts to cry anytime I do that. Her reaction tells me she loves the food I prepare for her."

Feeding time is expressed as a moment of joy, this is how some new moms shared their experiences with the introduction of complementary feeding as elucidated in the above excerpts.

\section{Theme 3: "A moment of stress"}

Again, a mutual theme among the respondents was the feeling of stress as captured in the excerpts below.

A mother described her experience as follows:

"Initiating complementary feeding is a full-time job on its own, no wonder Mother's Day is always special. I wash my baby's feeding bottle very well and keep it in hot water for some time. I also make sure every food I give is warm. These activities make a demand on time and energy. Sometimes he starts to feed and at a point stops, just a little time after he has paused he begins to cry which makes me think he wants to continue feeding, I then need to warm up the food again for him to feed again. He sometimes refuses to eat after I rewarm, I will then resort to giving him breastmilk."

Another finding from this study described initiating complementary feeding as "hectic".

Another mother had this to say:

"Feeding a baby is stressful, hmm, I sometimes have to prepare at least two different meals, keep in the warmer before I leave for work. I do not feed him myself, my mom does so. I will be at work and she will call me that he is rejecting the food prepared. In such situations, I will have to rush home for another option. Because of my baby's feeding behaviour, I often consult friends and family for more options to help me vary the foods I provide for complementary feeding."

A shared sentiment from the perspective of another mother:

"As for me, my baby only feeds when she is sleeping, she rejects almost every food I serve her when she is awake. So, what I do is to try hard to put her into a sleeping mood in order to feed her using the feeding bottle. She will sometimes wake up in the course of the feeding and reject whatever is remaining in the bottle. This makes feeding her difficult and time-consuming".

It was again stated by a different mother: 
"For my baby, feeding time is singing time. I have to constantly sing all the rhymes I know until she ends eating. While I sing my baby looks at my face and constantly opens her mouth for food. A friend once told me about a similar experience, then I was not a mother and I only told her she had too much time to waste singing and playing with the baby for her to eat. But now that I am a mother and going through a similar experience, I have understood her."

A young mother also shared her experience:

"In fact, if your baby begins to feed on complementary foods, it is not easy at all. Hmmm, it is so stressful. Anytime you move out you need to move with everything needed for her feeding and in a case where you leave something home, you will then be found wanting. Sometimes while you feed your baby, your dress may be stained and if you are dressed for a function, then you will have to return or find a way of looking your best."

In spite of the initiation of complementary feeding experiences being expressed by some first-time mothers as a feeling of added joy to motherhood, others expressed theirs as a hectic phase of motherhood as deduced from the preceding excerpts.

\section{Theme 4: "Opportunity to know your baby"}

In furtherance, an emerging theme among the respondents was the opportunity to know one's baby and this has been articulated in the excerpts below:

A new mother had this to share:

"I get satisfaction any time I feed my baby. From her reactions to the complementary foods, I give her, I am able to know what she wants and what she does not like to eat. I love to explore so knowing what my girl wants gives me the opportunity to try new recipes for my baby. When I try something and she accepts it, I feel very happy."

Another mother expressed:

"Anytime I give my girl an unusual mix she immediately shows a squeezed funny face indicating she is not familiar with the food given. She takes another scoop, then she begins to change the look on her face meaning she is ready to try. Such facial expressions often make me smile and she will smile back. When she accepts the food, I feel so relieved."

Sharing a similar sentiment, another new mother had this to say:

"My baby will always taste the food first and wait a while to decide whether to eat or not. If he likes the food, then he will open his mouth to be fed, but if he dislikes he will set his gum such that no food can enter his mouth. This has helped me to know what is liked and 
disliked by my baby. In fact, introducing your baby with complementary food is an interesting learning experience."

Complementary feeding has been expressed as an avenue to know what is liked and disliked by one's baby, these are shared experiences of some mothers as captured in the excerpts above.

Theme 5: "An avenue for fun and exposure"

The interview data gathered, again, revealed that the introduction of complementary feeding does create an avenue for fun and exposure, excerpts to depict that has been captured under this theme:

A new mother shared this:

"At first, I become too worried when my baby rejects her food but after some time when I identified her likes and dislikes, feeding has become fun. You know babies too have taste oo, hmmm and they know what they want and at what time they need it."

A similar sentiment was shared:

"I just love to observe my baby moving his mouth in a chewing mood. How he grasps the food from the spoon, eats and after opening his mouth for more is very funny and makes me laugh often when feeding him."

In spite of the array of feeling experienced by new mothers, it is still deduced that the introduction of complementary feeding brings some level of exposure to new moms and this is expressed in the just ended excerpts.

Data gathered on research question three revealed that experiences of first-time mothers on the initiation of complementary feeding were multifaceted ranging from mixed emotions and feelings to boredom and being an avenue for fun and exposure.

\section{Discussion of Results}

In order to guarantee optimal growth and development of newborns, complementary feeding technique is an essential topic of research, because complementary feeding habits impact many aspects of an infant's eating environment. The goal of this study was to learn more about complementary feeding from the perspective of first-time mothers. Findings from research question one revealed that most of the first mothers initiated complementary feeding before the recommended period of six months. This finding is consistent with previous studies by Alzaheb (2016) and Kronborg, Foverskov, and Vaeth (2014) who also discovered from their studies that mothers initiated complementary feeding before the recommended time. Relatedly, the common mantra of breast milk not being enough for the babies was the reason given in justification of the early initiation of 
complementary feeding. A look at the remarks by the first-time mothers in this study revealed that these mothers would have wished to follow the recommended guidelines relative to the initiation of complementary feeding. However, factors such as delayed production and flow of breast milk and job demands triggered the early initiation of complementary feeding. Impliedly, it could be said that because these first-time mothers were anxious and nervous, and therefore became swayed about the adequacy of their child's diet, they did not think about the possible dangers that may arise from not following the recommended guidelines. This is consistent with the observation by Walsh, Kearney, and Dennis (2015) who discovered that the quest to return to paid employment and concerns for breast milk supply was a cause for the early introduction of complementary feeding. Meanwhile, Rapley (2011) and Australia's National Health and Medical Research Council (2012) have strongly admonished against introducing complementary feeding before four months stating that this practice causes displacement of breast milk with foods with lower nutritional quality which also increases infants' risk of allergy development. This, therefore, suggests that a conscious effort is needed to assist new mothers to better comprehend complementary feeding practices.

Findings from research question two revealed that foods used in initiating complementary feeding were cereal-based foods. This finding is consistent with prior studies from Ghana by Abizari, Ali, Essah, Agyeiwaa, and Amaniampong (2017) and in Ethiopia by Abeshu, Lelisa and Geleta (2016) which have all disclosed that cereal-based foods are the most common foods that are offered to infants in these countries during complementary feeding stage because these cereal-based foods are readily available and relatively cheaper as compared to others. Nevertheless, it has been observed that these cereal-based foods contribute to early growth, it is also on record to have profound consequences on the infant's cognitive and physical development (Onwurafor, Ani, Nneka \& Ziegle, 2020). Findings from this research question also disclosed that the complementary foods initiated by the new mothers were not nutritionally balanced. This corroborates the findings by Karigi, Mutuli and Bukhala (2016) whose study on the sociocultural practices and beliefs influencing infants and young in Lubao, sub-location in Kakamega County revealed that it was a taboo for feeding infants with egg since it causes delayed speech and motor-skills development. However, it has been noted that denying children the consumption of eggs, a source of high biological protein value, and a cheaper protein food source compared with meat, fish and poultry, could increase their susceptibility to protein-energy malnutrition, exhibited in the form of kwashiorkor and marasmus.

Findings from research question three disclosed that the first-time mothers had varied experiences relative to the initiation of complementary feeding of their infants which were categorized into 5 themes. Evidence emerging from this theme "being a greenhorn at the start" suggests that these mothers were entirely novices initiating complementary feeding which in a way amounted to taking a risk. Again, it could be said that first-time mothers had to try different recipes to meet the preference of their babies. This is because mothers were attempting to figure out the shift from breastfeeding to 
supplemental feeding by "trial and error". Being a novice for this new phase of feeding may lead to taking risks during complementary feeding. Therefore, providing mothers with additional feeding education prior to commencing this phase could be one way to reduce the dangers of feeding by "trial and error." The theme "plethora of emotions and feeling" emerging from the study points to the fact that the initiation of complementary feeding gave mothers an array of emotions and feelings which to them was the beginning of the bonding experience between them and their babies. While some mother's expressed their array of feelings and emotions others were of the view that the initiation of complementary feeding is tiresome and this is emphasized as "a moment of stress". The excerpts from the interviews indeed describe the multiplicity of the experiences of first-time mothers, from being greenhorns at the start to the varying emotions and feelings and being stressful. Notwithstanding, the introduction of complementary feeding creating an avenue for mothers to know what their babies liked and disliked emerged as one of the experiences of the first-time mother towards complementary feeding. These experiences are consistent with studies by Matvienko-Sikar, Kelly, Sinnott, McSharry, Houghton, Heary, and Kearney (2017) who discovered varied experiences from mothers during complementary feeding

\section{Conclusions and Recommendations}

This study concludes that transitioning from exclusive breastfeeding to the introduction of complementary foods may have dire consequences for infants if not executed properly. This study established that first-time mothers did not exhibit a good understanding of the rationale behind exclusive breastfeeding as most of them initiated complementary feeding before the recommended period of six (6) months. Accordingly, this study recommends that the Public Health Departments of the hospitals should organize serious education during antenatal and postnatal visitations for mothers on the dangers associated with the early introduction and inappropriate complementary feeding practices. Again, mothers should be counselled to make them better prepared for the complexities associated with the initiation of infant complementary feeding practices. There is enough proof to conclude that cereal-based foods were mostly adopted by firsttime mothers for complementary feeding which could make them susceptible to protein and micro-nutrient deficiencies. Hence, first-time mothers should be educated on the inclusion of foods rich in protein, iron, zinc, phosphorus, magnesium, calcium, and vitamin B6 required for the healthy growth and development of the child. This could be done by Public Health Personnel through education during postnatal visits and by also deploying them into the communities. The myriad of feelings experienced by the firsttime mothers points to the fact that first-time mothers are not adequately prepared for the initiation of complementary feeding practices. As such, intensive complementary feeding education should run concurrently with breastfeeding education to be rendered during antenatal and postnatal visitations. Besides, the Public Health Department of the various hospitals in the municipality should provide an avenue for monitoring first-time 
mothers on the initiation of complementary feeding to share their experiences so as to resolve the challenges encountered thereof for improved complementary feeding practices.

\title{
Acknowledgements
}

The authors are grateful to the Faculty of Home Economics Education for the introductory letter given to facilitate data collection. Again, our sincere gratitude is extended to the Directorate of Health Services in the Effutu Municipality for the approval of the conduct of the study. Lastly, we say a big thank you to all public health officials for their continued support with data collection and also to the new mothers who allowed themselves to be participants of the study, we appreciate the in-depth information given for the enrichment of the paper.

\section{Conflict of Interest Statement}

The authors declare that they have no conflict of interest related to the study or the preparation of the manuscript.

\section{Funding}

There was no external funding received for this study.

\begin{abstract}
About the Author(s)
Janet Agyarkwaa Oti has an M. Phil degree in Food and Nutrition and is a lecturer in the Department of Food and Nutrition Education. Faculty of Home Economics Education, University of Education Winneba. Her research interest includes food safety, maternal and child nutrition, pregnancy and nutrition, adolescent nutrition and nutrition for the elderly.

Theresa Alexandra Amu has a PhD degree in Development Studies and is a Senior Lecturer in the Department of Family Life Management Education, Faculty of Home Economics Education, University of Education Winneba. She Teaches Family Theories and Gerontology, Family Relations Across Life Span, and Issues in Family Finance at the graduate level. At the undergraduate level, she teaches Marriage and Parenthood, Childcare and Development, Family Dynamics and Change, Family Financial Management and Consumer Education, and Family Life Education. Her research interest includes family studies, maternal and child health, and sanitation.
\end{abstract}

\section{References}

Abeshu, M. A., Lelisa, A., \& Geleta, B. (2016). Complementary Feeding: Review of Recommendations, Feeding Practices, and Adequacy of Homemade Complementary Food Preparations in Developing Countries - Lessons from Ethiopia. Frontiers in nutrition, 3,41. https://doi.org/10.3389/fnut.2016.00041 
Abizari, A. R., Ali, Z., Essah, C. N. et al. (2017). Use of commercial infant cereals as complementary food in infants and young children in Ghana. BMC Nutr 3, 72 https://doi.org/10.1186/s40795-017-0191-x

Agbozo, F., Colecraft, E., \& Ellahi, B. (2015). Impact of type of child growth intervention program on caregivers' child feeding knowledge and practices: a comparative study in Ga West Municipality, Ghana. Food science \& nutrition, 4(4), 562-572. https://doi.org/10.1002/fsn3.318

Alzaheb, R. A. (2016). Factors Associated with the Early Introduction of Complementary Feeding in Saudi Arabia. International journal of environmental research and public health, 13(7), 702. https://doi.org/10.3390/ijerph13070702

Australia's National Health \& Medical Research Council, (2012). Infant Feeding Guidelines. Canberra: National Health and Medical Research Council.

Awogbenja, M. D., \& Ugwuona, F. U. (2010). Feeding practices and nutritional status of under-five children in Nasarawa State, Nigeria. PAT, 6(1), 23-35.

Begin, F., \& Aguayo, V. (2017). First foods: Why improving young children's diets matter. Maternal \& Child Nutrition. 13. https://doi.org/10.1111/mcn.12528

Bentil, H. J., Steiner-Asiedu, M., \& Lartey, A. (2016). Comparison of the complementary feeding practices between mothers with twins and mothers with singletons. Pan African Medical Journal. 24,52. https://doi.org/10.11604/pamj.2016.24.52.8290

Boeije, H. (2010). Analysis in qualitative research. London: Sage Publications

Braun, V., \& Clarke, V. (2006). Using thematic analysis in psychology. Qualitative Research in Psychology, 3 (2). pp. 77-101. ISSN 1478-0887

Burns, N. \& Grove, S. K. (2011). Understanding nursing research: Building an evidence-based practice. ( $5^{\text {th }}$ ed.). Atlanta, GA: Elsevier.

Chapagain, R. H. (2013). Factors affecting complementary feeding practices of Nepali mothers for 6 months to 24 months children. Journal of Nepal Health Research Council, 11(24), 205-207.

Cook, E. J., Powell, F. C., Ali, N., Penn-Jones, C. Ochieng, B. \& Randhawa, G. (2020). Parents' experiences of complementary feeding among a United Kingdom culturally diverse and deprived community. Maternal and Child Nutrition, 17(2), $15-42$.

Corbin, J., \& Strauss, A. (2008). Basics of Qualitative Research: Techniques and Procedures for Developing Grounded Theory (3rd ed.). Thousand Oaks, CA: Sage. Organizational Research Methods, 12(3), 614617. https://doi.org/10.1177/1094428108324514

Creswell, J. (2002). Educational research: Planning, conducting, and evaluating quantitative and qualitative research. Upper Saddle River, NJ: Merrill Prentice Hall.

Creswell, J. W. \& Poth, C. N. (2018). Qualitative inquiry and research design choosing among five approaches. ( $4^{\text {th }}$ ed.). SAGE Publications, Inc., Thousand Oaks.

Denzin, N. K., \& Lincoln, Y. S. (eds.) (2011). The SAGE Handbook of Qualitative Research (5 ${ }^{\text {th }}$ ed.). Thousand Oaks, CA: SAGE Publications. 
Ethiopia Mini Demographic and Health Survey, (2019). Key indicators Ethiopian public health institute, Addis Ababa Federal Ministry of Health, Addis Ababa. The DHS Program, ICF, Rockville, Maryland, USA. https://www.dhsprogram.com/pubs/pdf/PR120/PR120.pdf

Ghana Statistical Service (GSS), Ghana Health Service (GHS), and ICF International. (2015). Ghana Demographic and Health Survey 2014. Rockville, Maryland, USA: GSS, GHS, and ICF International.

Gyampoh, S., Otoo, G. E. \& Aryeetey, R. N. (2014). Child feeding knowledge and practices among women participating in growth monitoring and promotion in Accra, Ghana. BMC Pregnancy Childbirth, 14(1), 180-192.

Harrison, M., Brodribb, W. \& Hepworth, J. (2017). A qualitative systematic review of maternal infant feeding practices in transitioning from milk feeds to family foods. Maternal Child Nutrition, 13(1), 12-36.

Haruna, A. B. (2018). Factors influencing optimal complementary feeding practices among Mothers of Children Aged 6-23 Months in the Ga South Municipality. (Unpublished Masters thesis, University of Ghana). URI: http://ugspace.ug.edu.gh/handle/123456789/26410

Karigi, L. N., Mutuli, L. A., Bukhala, P. (2016). Socio-cultural practices and beliefs influencing infant and young child feeding in Lubao sub-location Kakamega Country. J Nutr Health Food Eng. 568-571 DOI: 10.15406/jnhfe.2016.05.00160

Kimani-Murage, E. W., Fotso, J. C., Egondi, T., Abuya, B., Elungata, P., Ziraba, A. K., \& Madise, N. (2014). Trends in childhood mortality in Kenya: the urban advantage has seemingly been wiped out. Health \& Place, 29, 95-103.

Korir, J. K. (2013). Determinants of complementary feeding practices and nutrition status of children 6-23 months old in Korogocho slum, Nairobi County, Kenya. (Unpublished master's thesis) Nairobi: Kenyatta University.

Kostecka, M., Jackowska, I. \& Kostecka, J. (2020). Factors affecting complementary feeding of infants. A pilot study conducted after the introduction of new infant feeding guidelines in Poland. Nutrients, 13(1), 6-11.

Kronborg, H., Foverskov, E., \& Væth, M. (2014). Predictors for early introduction of solid food among Danish mothers and infants: an observational study. BMC pediatrics, 14, 243. https://doi.org/10.1186/1471-2431-14-243

Matvienko-Sikar, K., Kelly, C., Sinnott, C., McSharry, J., Houghton, C., Heary, C., Toomey, E., Byrne, M., \& Kearney, P. M. (2018). Parental experiences and perceptions of infant complementary feeding: a qualitative evidence synthesis. Obesity reviews: An official journal of the International Association for the Study of Obesity, 19(4), 501-517. https://doi.org/10.1111/obr.12653

Mokoria, A., Schonfeldtb, H. \& Hendriksc, S. L. (2017). Child factors associated with complementary feeding practices in Uganda. South African Journal of Clinical Nutrition 30(1), 7-14. 
Molla, M., Ejigu T., \& Nega. G. (2017). Complementary feeding practice and associated factors among mothers having children 6-23 months of age, Lasta District, Amhara Region, Northeast Ethiopia. Advances in Public Health. 2017, Article ID 4567829 https://doi.org/10.1155/2017/4567829

Mulat, E., Alem, G., Woyraw, W. \& Temesgen, H. J. B. N. (2019). Uptake of minimum acceptable diet among children aged 6-23 months in orthodox religion followers during fasting season in rural area, DEMBECHA, North West Ethiopia. BMC Nutrition, 5(1), 18-25.

Myers, M. D. (2009). Qualitative research in business \& management. Sage Publications Ltd. Njai, M. \& Dixey, R. (2013). A study investigating infant and young child feeding practices in Foni Kansala District, Western Region, Gambia. Journal of Clinical Medicine and Research 5(6), 71-79.

Onwurafor, E., Ani, J., Uchegbu, N., \& Ziegler, G. (2020). Quality evaluation of fermented Maize-based Complementary Foods as affected by amylase-rich mungbean malt. Journal of Food Stability. 3 (1): 26-37. 10.36400/J.Food.Stab.3.1.2020-0025.

Parahoo, K. (2006). Nursing research: Principles, process and issues. (2 ${ }^{\text {nd }}$ ed.). Palgrave Macmillan, London.

Patton, M. (2015). Qualitative research and evaluation methods. (4 $4^{\text {th }}$ ed.). Sage Publications, Thousand Oaks.

Rapley, G. (2011). Baby-led weaning: transitioning to solid foods at the baby's own pace. Community Practitioner, 84(6), 5.

Saaka, M., Larbi, A., Mutaru, S., \& Hoeschle-Zeledon, I. (2016). Magnitude and factors associated with appropriate complementary feeding among children 6-23 months in Northern Ghana. BMC Nutrition, 2(2),1-8.

Saldana, J. (2013). The Coding Manual for Qualitative Researchers $2^{\text {nd }}$ ed. Sage Publications Asia-Pacific Pte Ltd 3 Church Street \#10-04 Samsung Hub Singapore 049483

Saunders, M., Lewis, P. \& Thornhill, A. (2016). Research Methods for Business Students. (7th ed.). Pearson, Harlow.

Schmidt-Traub, G., Kroll, C., Teksoz, K., Durand-Delacre, D. \& Sachs, J. D. (2017). National baselines for the Sustainable Development Goals assessed in the SDG Index and Dashboards. Nature Geosci 10(1), 547-555.

Sekaran, U. \& Bougie, R. (2016). Research methods for business: A skill-building approach. (7th ed)., Wiley \& Sons, West Sussex.

Silverman, D. (2010). Quality in qualitative research. Doing Qualitative Research. Sage Publications. 268-291.

Trochim, W. M. (2006). Types of Reliability. Research Methods Knowledge Base, Web Center for Social Research Methods. https://www.socialresearchmethods.net/t/kb/reltypes.php

Udoh, E. E. \& Amodu, O. K. (2016). Complementary feeding practices among mothers and nutritional status of infants in Akpabuyo Area, Cross River State Nigeria. Springer Plus 5(1), 20-73.

United Nations Children Fund, (UNICEF, 2020). Levels and trends in child mortality. 
Walsh, A., Kearney, L., \& Dennis, N. (2015). Factors influencing first-time mothers' introduction of complementary foods: a qualitative exploration. BMC public health, 15, 939. https://doi.org/10.1186/s12889-015-2250-z

Whitehead, D. \& Annells, M. (2007). Sampling and collecting data in qualitative research. Sydney: Mosby-Elsevier.

World Health Organisation, (2018). Children: Improving survival and well-being. https://www.who.int/news-room/fact-sheets/detail/children-reducing-mortality.

World Health Organisation, (2015). Postnatal Care for Mothers and Newborns Highlights from the World Health Organization 2013 Guidelines. World Health Organization and Jhpiego 2015. All rights reserved. WHO/RHR/15.05

World Health Organization, (2010). Guiding principles for feeding of non-breastfed children. WHO: Geneva.

World Health Organization, (2017). Global strategy for infant and young child feeding. http://www.who.int/nutrition/topics/global strategy iycf/en/. 
Creative Commons licensing terms

Author(s) will retain the copyright of their published articles agreeing that a Creative Commons Attribution 4.0 International License (CC BY 4.0) terms will be applied to their work. Under the terms of this license, no permission is required from the author(s) or publisher for members of the community to copy, distribute, transmit or adapt the article content, providing a proper, prominent and unambiguous attribution to the authors in a manner that makes clear that the materials are being reused under permission of a Creative Commons License. Views, opinions and conclusions expressed in this research article are views, opinions and conclusions of the author(s). Open Access Publishing Group and European Journal of Public Health Studies shall not be responsible or answerable for any loss, damage or liability caused in relation to/arising out of conflicts of interest, copyright violations and inappropriate or inaccurate use of any kind content related or integrated into the research work. All the published works are meeting the Open Access Publishing requirements and can be freely accessed, shared, modified, distributed and used in educational, commercial and non-commercial purposes under a Creative Commons Attribution 4.0 International License (CC BY 4.0). 